\title{
Sistem Pendukung Keputusan Potensi Siswa Dengan Metode Fuzzy Multiple-Attribute Decision Making (FMADM) (Studi Kasus : Pada SDN Maccini 1 Makassar)
}

\author{
Syahriani Syam \\ Jurusan Teknik Informatika, Fakultas Teknik, Universitas Islam Syekh Yusuf, Jl. Mulana Yusuf No.10 \\ Tangerang Banten 15118, Indonesia (10pt normal italic) \\ ssyam@unis.ac.id
}

\begin{abstract}
Abstrak. Setiap siswa SDN Maccini 1 Makassar memiliki watak, pola pikir, emosi, kepribadian yang berbeda-beda, sangat sulit untuk mencari solusi pembelajaran yang baik untuk setiap siswa, dan cara berfikir siswa sekolah dasar yang masih belum fokus dalam suatu hal dapat mempersulit guru dalam memberikan keputusan solusi yang baik untuk setiap siswa. Dampaknya setiap siswa dalam pengembangan potensinya kurang efektif, karena metode pembelajaran yang tidak sesuai untuk siswa satu dengan siswa yang lain, perlunya peningkatan potensi setiap siswa untuk memaksimalkan potensi setiap siswa yang ada. Aplikasi Sistem Pendukung Keputusan sangat membantu dalam meningkatkan potensi setiap siswa, mempermudah guru dalam mengoptimalkan potensi siswa. Guru dapat lebih efisiensi waktu dalam menentukan potensi siswa di masa depan, Karena setiap siswa perlu meningkatkan kualitas diri, maka aplikasi ini sangat berguna untuk guru dalam meningkatkan potensi siswanya
\end{abstract}

Kata kunci: potensi, siswa, fuzzy

\begin{abstract}
Every student of SDN Maccini 1 Makassar has different character, mindset, emotion, personality, it is very difficult to find a good learning solution for each student, and the way of thinking of elementary school students who still not focus in one case can make it difficult for teachers in providing a good solution decisions for each student. The impact of each student in the development potential is less effective, because the method of learning is not suitable for students with one another, the need to increase the potential of each student to maximize the potential of every student there. Decision Support System application is very helpful in increasing the potential of each student, facilitate teachers in optimizing the potential students. Teachers can more time efficiency in determining the potential of students in the future, Because each student needs to improve the quality of self, then this application is very useful for teachers in increasing the potential of students
\end{abstract}

Keyword: Potensi, Siswa, Fuzzy

Keywords: potention, students, fuzzy

\section{Pendahuluan}

Sejak ditemukan pertama kali oleh Lotfi A. Zadeh pada tahun 1965, logika fuzzy telah dugunakan pada lingkup domain permasalahan yang cukup luas, seperti kendali proses, klasifikasi dan pencocokan pola, manajemen dan pengambilan keputusan, riset operasi, ekonomi dan sebagainya. Banyak metode yang digunakan untuk membantu dalam proses mengambil keputusan khususnya yang berdasarkan beberapa alternatif. Pengambilan keputusan harus mempertimbangkan alternatif yang menjadi faktor pendukung keberhasilan pengambilan keputusan sehingga menghasilkan keputusan yang optimal.

Metode kecerdasan buatan (Artificial Intellegence) sangat banyak digunakan dalam segala bidang. Teknologi softcomputing adalah sebuah bidang kajian banyak dikembangkan karena mempunyai keunggulan dalam penyelesain masalah yang mengandung ketidakpastian, ketidaktepatan dan kebenaran parsial, namun teknologi sangatlah dibutuhkan dalam hal kehidupan sehari-hari saat ini, dalam menentukan keputusan, menyelesaikan permasalahan, meberikan solusi dari 
permasalahan yang ada, sangatlah mempermudah dalam hal apapun saat ini.

Oleh sebab itu dibutuhkan metode-metode untuk meningkatkan efektifitas belajar setiap siswa di SDN Maccini 1 Makassar, dengan ini penulis merancang suatu aplikasi yang dapat mempermudah guru dalam mencari keputusan dalam hal potensi diri siswa dengan mempprediksi masa depan setiap siswa dan mencari data kemampuan setiap siswa yang perlu dikembangkan ataupun ditingkatkan dengan Tema Sistem Pendukung Keputusan Potensi Siswa Dengan Metode Fuzzy MultipleAttribute Decision Making (FMADM) (Studi Kasus : Pada SDN Maccini 1 Makassar).

\section{Identifikasi Masalah}

Dari uraian singkat di atas, penulis merumuskan beberapa masalah yang dihadapi yaitu sebagai berikut :

1. Sulit dalam pemberian keputusan yang sesuai untuk setiap siswa dalam pengembangan potensi siswa.

2. Potensi siswa tidak dapat diasah dengan baik.

3. Perataan metode belajar setiap siswa sama, padahal di sekolah dasar pengoptimalan potensi diri setiap siswa sangat penting untuk menggali potensi siswa tersebut.

\section{Batasan Masalah}

Agar Pembahasan terfokus pada inti pemasalahan maka penulis membatasa untuk proses rancangan Sistem pemberi keputusan ini, yaitu Input Data, untuk pengimputan data di batasi hanya menggunakan rata-rata nilai teori, praktek, hafalan, hitungan, dan kriteria tambahan yang menunjang keputusan yaitu jarak sekolah, cara berkomunikasi di sekolah, absensi, kepercayaan diri, sikap dan sopan santun di sekolah. Itu semua agar dalam penderajatan kriteria lebih optimal.

\section{Rumusan Masalah}

Dari uraian latar belakang diatas dapat diambil suatu perumusan masalah yaitu :

1. Bagaimana merancang aplikasi sistem pemberi keputusan berbasis Java di Keroncong Mas Permai ?

2. Apa kelebihan aplikasi sistem pemberi keputusan berbasis java?
3. Apakah sistem pemberi keptusan berbasis java lebih mempermudah guru dalam pengoptimalan potensi siswa?

\section{Sistem Pemberi Keputusan (SPK)}

Sistem Pemberi Keputusan atau Decision Support System (DSS) adalah bagian dari sistem informasi berbasis komputer (termasuk sistem berbasis pengetahuan (manajemen pengetahuan)) yang dipakai untuk memberikan keputusan dalam suatu organisasi atau perusahaan.

Dapat juga dikatakan sebagai sistem komputer yang mengolah data menjadi informasi untuk mengambil keputusan dari masalah semi-terstruktur yang spesifik. Sistem Pemberi Keputusan memiliki 5 metode:

a. Simple Additive Weighting (SAW)

b. Weighted Product (WP)

c. ELECTRE

d. Technique for Order Preference by Similiarity to Ideal Solution (TOPSIS)

e. Analytic Hierarchy Process (AHP)

f. Fuzzy Multiple Attribute Decision Making (FMADM)

Lima metode diatas adalah metode yang paling sering digunakan untuk permasalah sistem pemberi keputusan Fuzzy MultipleAttribute Decision Making, karena sangat kuat dalam pencarian data dengan bobot-boto yang sangat spesifik.

\section{Fuzzy Logic}

Fuzzy Logic adalah suatu cara yang tepat untuk memetakan suatu ruang input kedalam suatu ruang output. Skema Fuzzy adalah sebagai berikut:

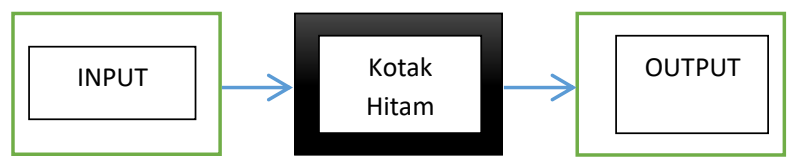

Gambar 1. Skema Logika Fuzzy

Pada gambar dapat diketahui bahwa antara input dan output terdapat sebuah kotak hitam yang sesuai. Ada beberapa cara atau metode yang mampu bekerja di kotak hitam tersebut, seperti sistem fuzzy, jaringan saraf tiruan, sistem linier, sistem pakar, persamaan diferensial, dan sebagainya.

Beberapa alasan mengapa logika fuzzy banyak digunakan saat ini diberbagai kasus. Alasan pemanfaatan logika fuzzy adalah: 
a. Sudah menjadi sifatnya yang kuat selama tidak membutuhkan ketepatan

b. Input yang bebas

c. Dapat diporgram untuk gagal dengan aman jika sensor arus balik dimatikan atau rusak

Control output adalah fungsi kontrol halis meskipun jarak variasi input uang cukup besar. Selama Fuzzy Logic Controller memproses aturan-aturan yang dibuat user uang memerintahkan system control target, ia dapat dimodifikasi dengan mudah untuk meningkatkan atau mengubah secara drastis perfoma system.

\section{Fuzzy Multi-Attribute Decision Making(FMADM)}

Fuzzy Multi-Attribute Decision Making adalah metode yang digunakan untuk mencari alternatif optimal dari sejumlah alternatif kriteria. Inti dari FMADM adalah menentukan nilai bobot untuk setiap atribut, kemudian dilanjutkan dengan proses perakingan yang menyeleksi alternatif yang sudah diberikan. Terdapat beberapa komponen umum yang digunakan yaitu:

a. Alternatif yaitu objek-objek yang berbeda dan memiliki kesempatan yang sama untuk dipilih oleh pengambil keputusan.

b. Atribut yang sering disebut sebagai karakteristik, komponen atau kriteria keputusan. Meskipun pada kebanyakan kriteria bersifat satu level, namun tidak menutup kemungkinan adanya sub-kriteria yang berhubungan dengan kriteria yang telah diberikan.

c. Konflik atar kriteria, beberapa kriteria biasanya memiliki konflik atara satu dengan yang lainnya.

d. Bobot keputusan (W), bobot keputusan ini menunjukan kepentingan rekatif dari setiap kriteria.

e. Matriks keputusan, suatu matriks keputusan $\mathrm{X}$ yang berukuran $\mathrm{m} \times \mathrm{n}$, berisi elemen $\mathrm{xij}$, yang merepresentasikan rating dari alternatif $\mathrm{A}_{\mathrm{i}}(\mathrm{i}=1,2, \ldots \mathrm{n}) \mathrm{n}$ adalah banyaknya jumlah alternatif, terhadapt kriteria $C_{j}(j=1,2, \ldots n) n$ $=$ adalah banyaknya jumlah kriteria.

f. Reprentasi permasalahan

Pada langkah reprentasi permasalahan, ada 3 aktivitas yang harus dilakukan, yaitu:

- Identifikasi tujuan dan alternatif keputusan

Tujuan keputusan dari permasalahan ini adalah dipilihnya masa depan yang sesuai dengan persentasi keberhasilan tertinggi. Jika ada $\mathrm{n}$ alternatif keputusan, maka alternatif-alternatif tersebut dapat ditulis sebagai $A=\{\mathrm{Ai} \mid \mathrm{i}=1,2,3, \ldots \mathrm{n}\}$.

- Identifikasi kumpulan kriteria

Jika ada k kriteria untuk menentukan pilihan dari beberapa alternatif keputusan maka dapat dituliskan $\mathrm{C}=\{\mathrm{Ct} \quad \mathrm{t}=$ $1,2,3, \ldots \mathrm{k}\}$. membangun struktur hirarki dari msalah tersebut berdasarkan pertimbangan-pertimbangan tertentu.

g. Evaluasi himpunan fuzzy

Pada langkah ini ada 3 aktifitasi yang harus dilakukan, yaitu:

- Memilih himpunan rating untuk bobotbobot kriteria, dan derajat kecocokan setiap alternatif dengan kriterianya. Secara umum, himpunan-himpunan rating terdiri atas 3 elemen, yaitu: variabel linguistik ( $\mathrm{x}$ ) yang merepresentasikan bobot kriteria, dan derjat kecocokan setiap alternatif dengan kriterianya; $\mathrm{T}(\mathrm{x})$ yang mereprentasikan rating dari variabel linguistik ; dan fungsi keanggotaan yang berhubungan dengan setiap eemen dari $\mathrm{T}(\mathrm{x})$. Sesudah himpunan rating ini ditentukan, selanjutnya harus ditentuan fungsi keanggotaan untuk setiap rating. Apabila dipilih fungsi keanggotaan segitiga, maka dapat digambarkan seperti Gambar 1.

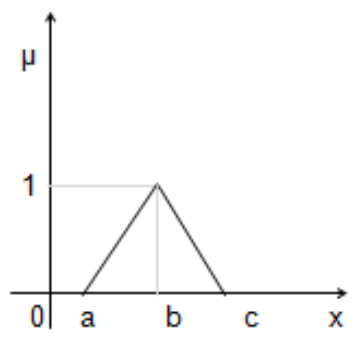

Gambar 2. Fungsi keanggotaan bilangan fuzzy segitiga

$$
\mu(x)=\left\{\begin{array}{l}
\frac{(x-a)}{(b-a)} ; a \leq b \leq b \\
\frac{(x-c)}{(b-c)} ; b \leq x \leq c \\
0 ; x \leq a \text { atau } x \geq c
\end{array}\right.
$$

Misalkan $\mathrm{W}_{\mathrm{t}}$ adalah bobot untuk criteria $\mathrm{C}_{\mathrm{t}}$; dan $\mathrm{S}_{\text {it }}$ adalah rating fuzzy untuk derahat kecocokan alternatif keputusan $A_{i}$ dengan kriteria $C_{t}$; dan $F_{i}$ adalah indeks 
kecocokan fuzzy dari alternaif $A_{i}$ yang merepresentasikan derjat kecocokan alternatif keputusan yang diperoleh dari hasil agregasi $S_{i t}$ dan $W_{t}$, dengan $i=$ $1,2,3, \ldots \mathrm{k}$ dan $\mathrm{t}=1,2,3, \ldots \mathrm{n}$.

- Mengevaluasi bobot-bobot kriteria, dan derajat kecocokan setiap alternatif dengan kriterianya.

- Mengagregasikan bobot-bobot kriteria dan derajat kecocoan setiap alternatif dengan kriterianya. Untuk mengagregasikan bobot-bobot kriteria dan derajat kecocokan setiap alternatif dengan kriterianya, dapat menggunakan beberapa metode agregasi seperti : mean, max, min, media, dan operator campuran. Apabila untuk melakukan agregasi terhadap hasil keputusan menggunakan metode mean, dan operator $*$ dan + adalah operator yang digunakan untuk perkalian dan penjumlahan fuzzy, maka $F_{i}$ dapat dirumuskan sebagai:

$\left[\left(\mathrm{S}_{1 \mathrm{k}} * \mathrm{~W}_{1}\right) \mathrm{x}\left(\mathrm{S}_{2 \mathrm{k}} * \mathrm{~W}_{2}\right) * \ldots *\left(\mathrm{~S}_{\mathrm{ik}} * \mathrm{~W}_{\mathrm{i}}\right)\right](1)$ Selanjutnya, dengan cara mensubtitusikan $S_{i t}$ dan $W_{t}$ dengan bilangan fuzzy segitiga yang sudah ditentukan, yaitu $\mathrm{S}_{\text {it }}=\left(\mathrm{o}_{\mathrm{it}}, \mathrm{p}_{\mathrm{it}}, \mathrm{q}_{\mathrm{it}}\right)$, dan $\mathrm{W}_{\mathrm{t}}=\left(\mathrm{a}_{\mathrm{t}}, \mathrm{b}_{\mathrm{t}}, \mathrm{c}_{\mathrm{t}}\right)$, maka $F_{i}$ dapat didekati sebagai $F_{i}=\left(Y, Q, Z_{i}\right)$ dengan:

$$
\begin{aligned}
\mathrm{Y}_{\mathrm{i}} & =\left(\frac{1}{\mathrm{k}}\right) \sum_{\mathrm{t}=1}^{\mathrm{k}}\left(\mathrm{o}_{\mathrm{it}} \mathrm{a}_{\mathrm{i}}\right) \\
\mathrm{Q}_{\mathrm{i}} & =\left(\frac{1}{\mathrm{k}}\right) \sum_{\mathrm{t}=1}^{\mathrm{k}}\left(\mathrm{p}_{\mathrm{it}} \mathrm{b}_{\mathrm{i}}\right) \\
\mathrm{Z}_{\mathrm{i}} & =\left(\frac{1}{\mathrm{k}}\right) \sum_{\mathrm{t}=1}^{\mathrm{k}}\left(\mathrm{q}_{\mathrm{it}} \mathrm{c}_{\mathrm{i}}\right)
\end{aligned}
$$

dimana $\mathrm{i}=1,2,3, \ldots, \mathrm{n}$

h. Menyeleksi alternatif yang optimal

Pada langkah ini ada 2 atifitas yang harus dilakukan, yaitu:

- Memprioritaskan alternatif keputusan berdasarkan hasil agregasi. Prioritas dari hasil agregasi dibutuhkan dalam rangka proses perangkingan alternatif keputusan. Karena hasil agregasi direpresentasikan dengan menggunakan bilangan fuzzy tersebut. Salah satu metode perangkingan untuk bilangan fuzzy tersebut. Salah satu metode perangkingan yang dapat digunakan adalah metode nilai total integral. Misalkan $\mathrm{G}$ adalah bilangan fuzzy segitiga, $G=(a, b, c)$, maka nilai total integral dapat dirumuskan sebagai berikut:

$$
I^{\propto}(G)=\left(\frac{1}{2}\right)(\propto c+b+(1-\propto) a)
$$

Nilai $\propto$ adalah indeks keoptimisan yang merepresentasikan derajat keoptimisan bagi pengambil keputusan $(0 \leq \propto \leq 1)$. Apabila $\propto$ semakin besar mengindikasikan bahwa derajat keoptimisannya semakin besar.

- Memilih alternatif keputusan dengan prioritas tertinggi sebagai alternatif yang optimal. Apabila $\mathrm{t}=1 \ldots \mathrm{n}$, dan ada beberapa bilangan fuzzy Gt maka semakin besar nilai $I^{\propto}(G)$ terbesar inilah yang menjadi tujuannya. Sehingga bisa ditentukan alternatif terbaik yang dipilih adalah yang memiliki nilai $I^{\propto}(G)$ terbesar.

Tujuan keputusan dari permasalah ini adalah dipilihnya masa depan siswa yang paling tinggi peluang yang dicapai.

\section{Bahan dan Metode:}

Lingkup penelitian mencakup spesifikasi dan keluaran serta proses dalam Fuzzy MultiAttribute Making (FMADM) sesuai yang dikembangkan oleh joo. Secara garis besar untuk menyelesaikan permasalahan dalam penentuan masa depan siswa di SDN Maccini 1 Makassar, dapat direprentasikan, dan materi kegiatan yang dilakukan adalah:

\section{Reprentasi permasalahan}

Pada langkah reprentasi permasalahan, ada 3 aktivitas yang harus dilakukan, yaitu:

\section{a. Identifikasi tujuan dan alternatif keputusan}

Tujuan keputusan dari permasalahan ini adalah dipilihnya masa depan yang sesuai dengan persentasi keberhasilan tertinggi. Jika ada $n$ alternatif keputusan, maka alternatif-alternatif tersebut dapat ditulis sebagai $\mathrm{A}=\{\mathrm{Ai} \mid \mathrm{i}=$ $1,2,3, \ldots \mathrm{n}\}$.

\section{b. Identifikasi kumpulan kriteria}

Jika ada $\mathrm{k}$ kriteria untuk menentukan pilihan dari beberapa alternatif keputusan maka dapat dituliskan $\mathrm{C}=\{\mathrm{Ct} \mid \mathrm{t}=1,2,3, \ldots \mathrm{k}\}$. membangun struktur hirarki dari msalah tersebut berdasarkan pertimbangan-pertimbangan tertentu.

\section{Evaluasi himpunan fuzzy}

Pada langkah ini ada 3 aktifitasi yang harus dilakukan, yaitu:

a. Memilih himpunan rating untuk bobot-bobot kriteria, dan derajat kecocokan setiap 
alternatif dengan kriterianya. Secara umum, himpunan-himpunan rating teridiri atas 3 elemen, yaitu: variabel linguistik (x) yang merepresentasikan bobot kriteria, dan derajat kecocokan setiap alternatif dengan kriterianya; $\mathrm{T}(\mathrm{x})$ yang mereprentasikan rating dari variabel linguistik ; dan fungsi keanggotaan yang berhubungan dengan setiap elemen dari $\mathrm{T}(\mathrm{x})$. Sesudah himpunan rating ini ditentukan, selanjutnya harus ditentuan fungsi keanggotaan untuk setiap rating. Apabila dipilih fungsi keanggotaan segitiga.

$$
\mu(x)=\left\{\begin{array}{l}
\frac{(x-a)}{(b-a)} ; a \leq b \leq b \\
\frac{(x-c)}{(b-c)} ; b \leq x \leq c \\
0 ; x \leq a \text { atau } x \geq c
\end{array}\right.
$$

Misalkan $\mathrm{W}_{\mathrm{t}}$ adalah bobot untuk criteria $\mathrm{C}_{\mathrm{t}}$; dan $S_{i t}$ adalah rating fuzzy untuk derahat kecocokan alternatif keputusan $A_{i}$ dengan kriteria $C_{t}$; dan $F_{i}$ adalah indeks kecocokan fuzzy dari alternaif $A_{i}$ yang merepresentasikan derjat kecocokan alternatif keputusan yang diperoleh dari hasil agregasi $S_{i t}$ dan $W_{t}$, dengan $i=1,2,3, \ldots k$ dan $\mathrm{t}=1,2,3, \ldots \mathrm{n}$.

b. Mengevaluasi bobot-bobot kriteria, dan derajat kecocokan setiap alternatif dengan kriterianya

c. Mengagregasikan bobot-bobot kriteria dan derajat kecocoan setiap alternatif dengan kriterianya. Untuk mengagregasikan bobotbobot kriteria dan derajat kecocokan setiap alternatif dengan kriterianya, dapat menggunakan beberapa metode agregasi seperti : mean, max, min, media, dan operator campuran. Apabila untuk melakukan agregasi terhadap hasil keputusan menggunakan metode mean, dan operator * dan + adalah operator yang digunakan untuk perkalian dan penjumlahan fuzzy, maka $\mathrm{F}_{\mathrm{i}}$ dapat dirumuskan sebagai:

$\mathrm{F}_{\mathrm{i}}=\left(\frac{1}{\mathrm{k}}\right)\left[\left(\mathrm{S}_{1 \mathrm{k}} * \mathrm{~W}_{1}\right) \mathrm{x}\left(\mathrm{S}_{2 \mathrm{k}} * \mathrm{~W}_{2}\right) * \ldots *\right.$

$\left.\left(\mathrm{S}_{\mathrm{ik}} * \mathrm{~W}_{\mathrm{i}}\right)\right]$

Selanjutnya, dengan cara mensubtitusikan $S_{i t}$ dan $W_{t}$ dengan bilangan fuzzy segitiga yang sudah ditentukan, yaitu $S_{i t}=\left(o_{i t}, p_{i t}, q_{i t}\right)$, dan $\mathrm{W}_{\mathrm{t}}=\left(\mathrm{a}_{\mathrm{t}}, \mathrm{b}_{\mathrm{t}}, \mathrm{c}_{\mathrm{t}}\right)$, maka $\mathrm{F}_{\mathrm{i}}$ dapat didekati sebagai $F_{i}=\left(Y, Q, Z_{i}\right)$ dengan

$$
\begin{aligned}
& \mathrm{Y}_{\mathrm{i}}=\left(\frac{1}{\mathrm{k}}\right) \sum_{\mathrm{t}=1}^{\mathrm{k}}\left(\mathrm{o}_{\mathrm{it}} \mathrm{a}_{\mathrm{i}}\right) \\
& \mathrm{Q}_{\mathrm{i}}=\left(\frac{1}{\mathrm{k}}\right) \sum_{\mathrm{t}=1}^{\mathrm{k}}\left(\mathrm{p}_{\mathrm{it}} \mathrm{b}_{\mathrm{i}}\right) \\
& \mathrm{Z}_{\mathrm{i}}=\left(\frac{1}{\mathrm{k}}\right) \sum_{\mathrm{t}=1}^{\mathrm{k}}\left(\mathrm{q}_{\mathrm{it}} \mathrm{c}_{\mathrm{i}}\right) \\
& \operatorname{dimana} \mathrm{i}=1,2,3, \ldots, \mathrm{n}
\end{aligned}
$$

\section{Menyeleksi alternatif yang optimal}

Pada langkah ini ada 2 aktifitas yang harus dilakukan, yaitu:

a. Memprioritaskan alternatif keputusan berdasarkan hasil agregasi. Prioritas dari hasil agregasi dibutuhkan dalam rangka proses perangkingan alternatif keputusan. Karena hasil agregasi direpresentasikan dengan menggunakan bilangan fuzzy tersebut. Salah satu metode perangkingan untuk bilangan fuzzy tersebut. Salah satu metode perangkingan yang dapat digunakan adalah metode nilai total integral. Misalkan $\mathrm{G}$ adalah bilangan fuzzy segitiga, $\mathrm{G}=$ $(a, b, c)$, maka nilai total integral dapat dirumuskan sebagai berikut:

$$
\left.I^{\propto}(G)=\left(\frac{1}{2}\right) \propto c+b+(1-\propto) a\right)
$$

Nilai $\propto$ adalah indeks keoptimisan yang merepresentasikan derajat keoptimisan bagi pengambil keputusan $(0 \leq \propto \leq 1)$. Apabila $\propto$ semakin besar mengindikasikan bahwa derajat keoptimisannya semakin besar.

b. Memilih alternatif keputusan dengan prioritas tertinggi sebagai alternatif yang optimal. Apabila $\mathrm{t}=1 \ldots \mathrm{n}$, dan ada beberapa bilangan fuzzy Gt maka semakin besar nilai $I^{\propto}(G)$ terbesar inilah yang menjadi tujuannya. Sehingga bisa ditentukan alternatif terbaik yang dipilih adalah yang memiliki nilai $I^{\propto}(G)$ terbesar. Tujuan keputusan dari permasalah ini adalah dipilihnya masa depan siswa yang paling tinggi peluang yang dicapai.

c. Pemilihan bahan analisa untuk metode FMADM

Kriteria yang terhubung dengan pendekatan masa depan siswa adalah sebagai berikut: 
Tabel 1. Pilihan Kriteria Yang Mendasari Potensi Siswa

\begin{tabular}{cl}
\hline & \multicolumn{1}{c}{ Kriteria } \\
\hline 1 & Komunikasi di sekolah \\
\hline & $\begin{array}{l}\text { Rata-rata nilai pelajaran } \\
\text { teori }\end{array}$ \\
\hline 3 & $\begin{array}{l}\text { Rata-rata nilai pelajaran } \\
\text { praktek }\end{array}$ \\
\hline 4 & $\begin{array}{l}\text { Rata-rata nilai pelajaran } \\
\text { menghitung }\end{array}$ \\
\hline 5 & $\begin{array}{l}\text { Rata-rata nilai pelajaran } \\
\text { menghafal }\end{array}$ \\
\hline 6 & $\begin{array}{l}\text { Sikap siswa / sopan } \\
\text { santun }\end{array}$ \\
\hline 7 & Kepercayaan diri \\
\hline 8 & Absensi \\
\hline
\end{tabular}

Tabel 2. Kriteria Potensi Siswa $\left(\mathrm{C}_{\mathrm{i}}\right)$

\begin{tabular}{cl}
\hline Kriteria & \multicolumn{1}{c}{ Nama Kriteria } \\
\hline C1 & Komunikasi di sekolah \\
\hline C2 & Rata-rata nilai pelajaran teori \\
\hline C3 & Rata-rata nilai pelajaran praktek \\
\hline C4 & Rata-rata nilai pelajaran menghitung \\
\hline C5 & Rata-rata nilai pelajaran menghafal \\
\hline C6 & Sikap dan Sopan Santun \\
\hline C7 & Kepercayaan diri \\
\hline C8 & Jumlah Absensi \\
\hline
\end{tabular}

Semua kriteria menggunakan 3 nomor fuzzy low $(L)$, medium $(M)$, dan high $(H)$.

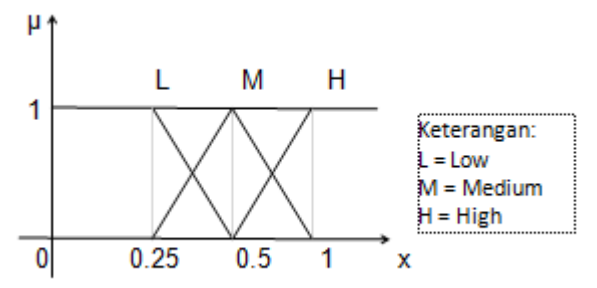

Gambar 3. Keseluruhan variabel fuzzy linguistic dan nomor fuzzy

Variabel linguistik yang direpresentasikan dengan bilangan fuzzy segitiga sebagai berikut:

- $\mathrm{L}=(0,0.25,0.5)$

- $\mathrm{M}=(0.25,0.5,1)$

- $\mathrm{H}=(0.5,1,1)$

Derajat kecocokan alternatif-alternatif dengan kriteria keputusan yang direpresentasikan dengan bilangan fuzzy segitiga sebagai berikut:
- $\mathrm{L}=(0,0.25,0.5)$

- $\mathrm{M}=(0.25,0.5,1)$

- $\mathrm{H}=(0.5,1,1)$

Tabel 3. Variable Fuzzy Linguistic and correspondent fuzzy number untuk komunikasi di sekolah(C1)

\begin{tabular}{lc}
\hline \multicolumn{1}{c}{$\begin{array}{l}\text { Komunikasi di } \\
\text { sekolah }(\text { Kom })\end{array}$} & $\begin{array}{c}\text { Variabel } \\
\text { linguistik }\end{array}$ \\
\hline $\begin{array}{l}\text { Kom }=\text { tidak } \\
\text { pernah }\end{array}$ & Low \\
\hline Kom $=$ jarang & Medium \\
\hline Kom $=$ Sering & High \\
\hline
\end{tabular}

Tabel 4. Variable Fuzzy Linguistic and correspondent fuzzy number untuk rata-rata pelajaran teori $(\mathrm{C} 2)$

\begin{tabular}{cc}
\hline $\begin{array}{l}\text { Rata-rata nilai } \\
\text { pelajaran teori } \\
\text { (Teori) }\end{array}$ & Variabel linguistik \\
\hline Teori $<60$ & Low \\
\hline Teori $60-80$ & Medium \\
\hline Teori $>80$ & High \\
\hline
\end{tabular}

Tabel 5. Variable Fuzzy Linguistic and correspondent fuzzy number untuk rata-rata nilai $\operatorname{praktek}(\mathrm{C} 3)$

\begin{tabular}{cc}
\hline $\begin{array}{c}\text { Rata-rata nilai } \\
\text { pelajaran praktek } \\
\text { (Praktek) }\end{array}$ & $\begin{array}{c}\text { Variabel } \\
\text { linguistik }\end{array}$ \\
\hline Praktek $<50$ & Low \\
\hline Praktek $50-70$ & Medium \\
\hline Praktek $>70$ & High \\
\hline
\end{tabular}

Tabel 6. Variable Fuzzy Linguistic and correspondent fuzzy number untuk rata-rata nilai menghitung $(\mathrm{C} 4)$

\begin{tabular}{cc}
\hline $\begin{array}{c}\text { Rata-rata nilai } \\
\text { pelajaran } \\
\text { menghitung } \\
\text { (Hitung) }\end{array}$ & $\begin{array}{c}\text { Variabel } \\
\text { linguistik }\end{array}$ \\
\hline Hitung <50 & Low \\
\hline Hitung 50 - 70 & Medium \\
\hline Hitung $>70$ & High \\
\hline
\end{tabular}

Tabel 7. Variable Fuzzy Linguistic and correspondent fuzzy number untuk rata-rata nilai menghafal(C5)

\begin{tabular}{cc}
\hline $\begin{array}{c}\text { Rata-rata nilai } \\
\text { menghaf (Hafal) }\end{array}$ & $\begin{array}{c}\text { Variabel } \\
\text { linguistik }\end{array}$ \\
\hline Hafal $<60$ & Low \\
\hline Hafal $60-80$ & Medium \\
\hline Hafal $>80$ & High \\
\hline
\end{tabular}


Tabel 8. Variable Fuzzy Linguistic and correspondent fuzzy number untuk sikap dan sopan santun (C6)

\begin{tabular}{cc}
\hline $\begin{array}{c}\text { Sikap dan Sopan } \\
\text { Santun (Sikap) }\end{array}$ & $\begin{array}{c}\text { Variabel } \\
\text { linguistik }\end{array}$ \\
\hline Sikap = Kurang & Low \\
\hline Sikap = Baik & Medium \\
\hline $\begin{array}{l}\text { Sikap = Sangat } \\
\text { Baik }\end{array}$ & High \\
\hline
\end{tabular}

Tabel 9. Variable Fuzzy Linguistic and correspondent fuzzy number untuk Kepercayaan diri (C7)

\begin{tabular}{cc}
\hline $\begin{array}{c}\text { Kepercayaan diri } \\
(\mathrm{PD})\end{array}$ & $\begin{array}{c}\text { Variabel } \\
\text { linguistik }\end{array}$ \\
\hline $\mathrm{PD}=$ Kurang & Low \\
\hline $\mathrm{PD}=$ Biasa & Medium \\
\hline $\mathrm{PD}=$ Sangat Baik & High \\
\hline
\end{tabular}

Tabel 10. Variable Fuzzy Linguistic and correspondent fuzzy number untuk absensi(C8)

\begin{tabular}{|c|c|}
\hline Absensi & $\begin{array}{l}\text { Variabel } \\
\text { linguistik }\end{array}$ \\
\hline Absensi <60\% & Low \\
\hline $\begin{array}{l}\text { Absensi 60\% - } \\
80 \%\end{array}$ & Medium \\
\hline Absensi > 80\% & High \\
\hline
\end{tabular}

III. Hasil dan Pembahasan Implementasi Sistem

Langkah pertama yang harus di lakukan yaitu memasukkan nolai dari setiap variable yang mewakili nilai dari potensi siswa sehingga di harapkan setelah semua di input akan muncul keputusan untuk mengetahui Potensi siswa tersebut.

\section{Interface Aplikasi}

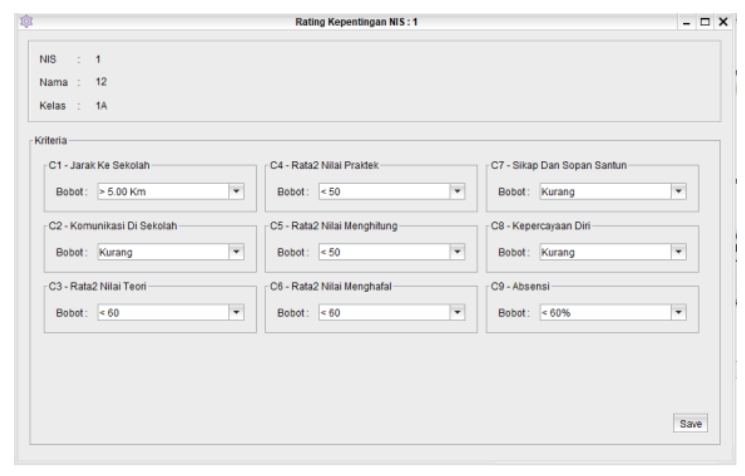

Gambar 4. Interface Aplikasi

\section{Kesimpulan}

Aplikasi Sistem Pendukung Keputusan sangat membantu dalam meningkatkan potensi setiap siswa, mempermudah guru dalam mengoptimalkan potensi siswa. Guru dapat lebih efisiensi waktu dalam menentukan potensi siswa di masa depan, Karena setiap siswa perlu meningkatkan kualitas diri, maka aplikasi ini sangat berguna untuk guru dalam meningkatkan potensi siswanya.

\section{Daftar Pustaka}

Jogiyanto. (2005). Analisis dan Desain Sistem Informasi. Yogyakarta: Penerbit Andi

Kusumadewi, Sri, Hartati, S., Harjoko A., dan Wardoyo, R.(2006). Fuzzy Multi-Attribute Decision Making (Fuzzy MADM). Yogyakarta: PT. Graha Ilmu, 2006

Mulyanto.(2009). Sistem Informasi dan Aplikasi. Yogyakarta: Pustaka Pelajar

Raymond McLeod. (2003). Sistem Informasi Manajemen. Hendra Teguh .Yogyakarta: PT. Graha Ilmu 